\title{
Work-related musculoskeletal disorders among nurses and midwives at a munici- pal health facility in Ghana
}

\author{
Hosea Boakye ${ }^{1}$, Bridget Numarce ${ }^{1}$, Juliana O. Ameh ${ }^{2}$ and Ajediran I. Bello ${ }^{3}$ \\ Ghana Med J 2018; 52(4): 228-234 doi: http://dx.doi.org/10.4314/gmj.v52i4.10
}

\author{
${ }^{1}$ Department of Physiotherapy, LEKMA Hospital; Accra \\ ${ }^{2}$ Paediatric Department, LEKMA Hospital; Accra \\ ${ }^{3}$ Department of Physiotherapy, School of Biomedical and Allied Health Sciences, College of Health Sciences, \\ University of Ghana, Legon, GHana
}

Corresponding author: Hosea Boakye

E-mail: hoseaboakye@yahoo.com

Conflict of interest: None declared

\section{SUMMARY}

Background: To determine the prevalence of work-related musculoskeletal disorders (WMSDs) among nurses and midwives, the associated job risk factors and the adopted coping strategies so as to provide baseline information in Ghana.

Design: A cross-sectional study.

Participants: One hundred and five (105) registered general nurses (RGN), 16 registered community health nurses $(\mathrm{RCHN})$ and 13 registered midwives (RM) were purposively recruited for the study in Ledzokuku-Krowor Municipal (LEKMA) Hospital, in the Greater Accra Region of Ghana.

Interventions: An adapted self-administered questionnaire was used to obtain information regarding demographics, prevalence and pattern of WMSDs, associated job risk factors and the reported coping strategies commonly employed by the participants. Point- prevalence of WMSDs, coping strategies and risk factors were summarized with percentage. The prevalence was further analyzed with regression analysis to determine its correlation with BMI, age, years of experience and type of profession at $\mathrm{p}<0.05$ level of significance.

Results: The 12-months prevalence was $79.0 \%, 53.8 \%$ and $18.8 \%$ for the RGN, RM, and RCHN respectively. Lifting or transferring of dependent patients $70(52.1 \%)$, inadequate training on injury prevention $63(46.5 \%)$ and working in awkward or cramped positions 53(39.6\%) were the most perceived job risk factors. Forty-six (34.3\%) participants commonly sought assistance from colleagues in handling heavy patients, 44(32.8\%) modified their positions and $27(20.3 \%)$ modified their caring procedure as coping strategies.

Conclusion: There was high point prevalence of self-reported WMSDs among the sampled nurses and midwives and lifting of patients was identified as the major risk factor. The findings have implication for body mechanics know-how of the nurses and midwives.

Funding: LEKMA Hospital

Keywords: Work-related musculoskeletal disorders, coping strategies, nursing, midwifery

\section{INTRODUCTION}

Work-related Musculoskeletal Disorders (WMSDs) are isolated or combined disorders in the muscles, tendons, ligaments, joints, cartilage or spinal disc characterized by discomfort, impairment, disability or persistent pain caused or aggravated mainly by the performance of work and the effects of the immediate environment in which work is carried out. ${ }^{1,2}$

Irrespective of the types of physical jobs, the disorders often occur in the low back, neck, shoulder and hand/wrist which often cause temporary or permanent occupational disabilities. ${ }^{2}$ WMSDs could result in decreased productivity, increased absenteeism rates, transfer to another job, jeopardizing companies' production capacity. ${ }^{3}$ It could invariably lead to more considerable expenses to treat sufferers, settle indemnity lawsuits and rehabilitate the precipitated disability than any other group of non-communicable health challenges with a considerable economic toll on the individual, the organization and the society as a whole. ${ }^{4}$

Work-related musculoskeletal disorders are common among health care workers ${ }^{5,6,7}$ of which nurses and midwives form the main thrust workforces globally. ${ }^{8}$ The etiology of WMSDs among nurses and midwives have been attributed to many intrinsic and extrinsic factors. ${ }^{6,9}$ 
The most documented extrinsic factors are physical demands of the nursing and midwifery professions which includes bending, twisting and turning to carry out routine procedures such as bathing, dressing, injecting seating and transferring the patient. ${ }^{1,10,11,12}$ Conversely, obesity and poor conditioning status have been reported as the most important intrinsic risk factors among these health workers population. ${ }^{11,13}$

Current literatures have indicated that there is a global shortage of nurses and midwives and the situation is predicted to worsen as many nurses and midwives quit the profession or retire prematurely due to numerous occupational hazards. ${ }^{2,14}$ According to the WHO's world health statistics, ${ }^{15}$ ratio of nurses per 10,000 populations of some Africa countries are as follows: Benin 7.7, Burkina Faso 5.7, Cameroon 4.4, Cape Verde 5.6, Central African Republic 2.6, Congo 8.2, Cote d'Ivoire 4.8, Ethiopia 2.5, Guinea-Bissau 5.9, Kenya 8.6, Malawi 3.4, Mali 4.3, Mozambique 4.1, Nigeria 16.1, Papua New Guinea 5.7, Togo 2.7, Zambia 7.8 and Ghana 9.3. ${ }^{16}$

In addition, the facts and figures of the Health Sector in Ghana ${ }^{16}$ indicated that the nurse to population ratio is 1:1000. These suggest that most health facilities in Ghana are under staffed with nurses and midwives which may expose the few available staff to overwork and burnout thus predisposing them to very high risk of WMSDs. However, there is no clear-cut documented prevalence of WMSDs either on local or general population.

Given the predisposition of nurses and midwives to the risk factors of WMSDs, pragmatic health preventive measures becomes imperative to modify patterns of working so as to avoid undue occupational stress on the staff and eventual rise in the incidence of these disorders. ${ }^{17}$ To implement any meaningful healthcare measure in a given population however, there is the need for sufficient information about the epidemiology of such health condition and its determinants. Although several authors have reported the prevalence of WMSDs among nurses and midwives in the Western world and some parts of Africa, ${ }^{1,2,6,7,18,19}$ there is dearth of literature on prevalence of WMSDs in Ghana for referencing.

This study therefore sought to determine the prevalence of WMSDs in connection with the demographic characteristics, the associated job risk factors and the coping strategies toward reducing the risk of developing WMSDs among nurses and midwives in LEKMA Hospital Ghana.

\section{METHODS}

\section{Participants}

The study included all registered general nurses (RGN), community health nurses (RCHN) and midwives (RM) working at LEKMA Hospital. They were recruited through purposive sampling technique. Nurses and midwives who are in active service with at least one year of working experience were included in the study. The study excluded nurses and midwives with previous history of musculoskeletal disorder before entering the nursing profession and visiting nurses who were on experiential learning.

\section{Design and Setting}

This was an institution-based cross-sectional study. The study was carried out at Ledzokuku-Krowor Municipality (LEKMA), a suburb of Accra in the greater Accra Region, with an estimated population of 227,932. The Hospital, which is located at the municipality was chosen as the study center being the largest health facility in the area and serves as the main referral center.

\section{Instrument for data collection}

A previously validated questionnaire was adapted for this study..$^{1,7}$ To ascertain the reliability and validity of the questionnaire in the local context, an academic Staff of the University of Ghana, (who was not part of the investigators) peer reviewed the questionnaire. Following the suggestions by the peer reviewer, the questionnaire was pre-tested with a pilot study among 20 nurses in a different hospital. Analysis of the responses from the pilot study indicated that the tool was reliable and valid, hence no re-test was conducted, and the questionnaire was adapted and used for data collection.

The questionnaire was self-administered and comprised four sections as follows: Section A sought sociodemographic data such as age, height, weight, and gender from participants. Section B consisted of questions on occupational health in nursing practice and collated general information on years of practice, work status, work setting, practice specialty, patient population, and nursing activities. The symptom-survey segment of the occupational health in nursing practice section consisted of questions referring to nine body areas. The body areas were 3 upper limb segments (Shoulders, elbows, wrists/hands/thumb), 3 lower limb segments (Hips/thighs, knees, ankles/feet), and 3 trunk segments (Neck, upper back and lower back). Section C contained items on perceptions on job risk factors that may contribute to the development of work-related musculoskeletal disorders while Section D sought information on coping strategies toward reducing the risk for development of WMSDs among the nurses. The questionnaire took approximately $10-15$ minutes to complete. 


\section{Procedure for data collection}

Ethical approval was sought from the Ghana Health Service Ethical Review Committee on research involving human subjects (Reference number: GHS/RDD/ERC/ADMIN/APP 630). Written permission was obtained from the Management of the LEKMA Hospital and the Nursing Administration.

Accompanied by an information sheet explaining the rationale of the study, copies of the questionnaire were distributed to the nurses and midwives who consented to participate in the study by 3 Research Assistants (RA).

In order not to interfere with their work and busy schedules, the participants were given a maximum of 2 weeks to complete the questionnaires. They were implored to avoid interacting with colleagues for information on the subject matter while completing the questionnaire. Within the stipulated time, participants were reminded twice through text messages. The questionnaires were collected by the three RA.

\section{Data Analysis}

Data obtained from the participants were entered into the Statistical Package for Social Sciences (SPSS) version 22 software. Participants' socio-demographic data such as ages and years of experience were summarized with mean, ranges and standard deviation while responses on coping strategies, prevalence and risk factors of WMSDs were presented with percentages.

Further exploration of prevalence was performed with logistic regression analysis to determine its relationship with their body mass index (BMI), years of experience, type of profession and age of the participants. Additionally, Chi Square analysis was employed to find the association between the prevalence and the number of hours participants work per week. The $\alpha$ level was set at 0.05 .

\section{RESULTS}

Two hundred (200) copies of the questionnaire were distributed among the participants in the study. Researchers were only able to retrieve 151 indicating a response rate of $75.5 \%$. However, $17(11.3 \%$ ) of the retrieved questionnaires were invalid for final analysis due to incomplete data.

\section{Demographic Characteristics of Participants}

The mean age of the participants was $33.03 \pm 9.65$ years with a range of 20 and 60 years. Females were 123 $(91.8 \%)$ of all the participants. The mean BMI of the participants was given as $27.53 \pm 6.04 \mathrm{~kg} / \mathrm{m}^{2}$. Most of the participants, $84(62.7 \%)$ had no post nursing qualification. One hundred and thirty $(98.5 \%)$ were full time employees while $2(1.5 \%)$ were part time employees.
All the other demographic characteristics of the participants such as age, years of experience, type of profession, BMI and number of working hours per week are represented in Table 1.

Table 1 Demographic characteristics of the participants

\begin{tabular}{|c|c|c|}
\hline Demographics & Categories & Frequency $(\%)$ \\
\hline \multirow[t]{2}{*}{ Gender } & Male & $11(8.2)$ \\
\hline & Female & $123(91.8)$ \\
\hline \multirow[t]{4}{*}{ Age } & $20-30$ & $66(49.3)$ \\
\hline & $31-40$ & $47(35.1)$ \\
\hline & $41-50$ & $11(8.2)$ \\
\hline & $51-60$ & $10(7.5)$ \\
\hline \multirow[t]{7}{*}{ Years of Experience } & $0-5$ & $74(55.2)$ \\
\hline & $6-10$ & $32(23.9)$ \\
\hline & $11-15$ & $14(10.4)$ \\
\hline & $16-20$ & $4(3.0)$ \\
\hline & $21-25$ & $2(1.5)$ \\
\hline & $26-30$ & $3(2.2)$ \\
\hline & $41+$ & $5(3.7)$ \\
\hline \multirow[t]{3}{*}{ Nursing Rank } & Nurse & $105(78.4)$ \\
\hline & Midwife & $13(9.7)$ \\
\hline & Community Nurse & 16(11.9) \\
\hline \multirow[t]{3}{*}{ BMI Categories } & $18.50-24.99$ & $52(38.8)$ \\
\hline & $25.00-29.99$ & $46(34.3)$ \\
\hline & 30.00 and more & $36(26.9)$ \\
\hline $\begin{array}{l}\text { Working Hours per } \\
\text { week }\end{array}$ & $\begin{array}{l}26-30 \\
31-35 \\
36-40 \\
41-45 \\
46-50\end{array}$ & $\begin{array}{l}6(4.5) \\
64(47.8) \\
29(21.6) \\
28(20.9) \\
7(5.2)\end{array}$ \\
\hline
\end{tabular}

Prevalence of the Work-related Musculoskeletal Disorders

The overall 12-month prevalence of WMSDs in this study was $69.4 \%$. One hundred and nine $(81.3 \%)$ of the participants reported that they have experienced workrelated musculoskeletal pain or discomfort at some time in their occupational life.

With regards to the 12-month prevalence of the different professions, RGN reported the highest prevalence of $79.0 \%$, followed by the RM with a 12- month prevalence of $53.8 \%$ and the RCHN with the least prevalence given as $18.8 \%$.

Table 2 Distribution of WMSD prevalence in different anatomical regions

\begin{tabular}{|l|l|l|}
\hline Body part & Number & Percentage \\
\hline Lower back & 67 & $72.0 \%$ \\
\hline Neck & 37 & $39.8 \%$ \\
\hline Upper back & 35 & $37.6 \%$ \\
\hline Knee & 25 & $26.9 \%$ \\
\hline Hips/Thighs & 25 & $26.9 \%$ \\
\hline Shoulder & 24 & $25.8 \%$ \\
\hline Wrist/Hand & 21 & $22.6 \%$ \\
\hline Ankles & 20 & $21.5 \%$ \\
\hline Thumb & 5 & $5.4 \%$ \\
\hline Elbow/Forearm & 4 & $4.3 \%$ \\
\hline
\end{tabular}


Out of the 93 participants who reported WMSDs in the last 12 months, 57(61.3\%) have had self-medication, $48(51.6 \%)$ have sought treatment from physicians while $23(24.7 \%)$ have visited the physiotherapist for remedy to their pain occasioned by WMSDs. The three most affected body parts were the lower back $67(72.0 \%)$, the neck 37(39.8\%) and the upper back 35(37.6\%) as shown in Table 2.

Associations of some selected socio-demographic variables of the participants and the prevalence of WMSDs

Logistic regression analysis was performed to test the relationship of the point prevalence of WMSDs with BMI, age, years of experience and type of profession. There was a significant relationship $(\mathrm{p}<0.05)$ between the 12-month prevalence and the type of profession as shown in Table 3.

Table 3 Binary Logistic regression of significant variable and prevalence of WMSD

\begin{tabular}{|c|c|c|c|c|c|}
\hline Variable & Coefficient & \multirow[t]{2}{*}{ OR } & \multicolumn{2}{|c|}{$\begin{array}{l}\text { 95\% C.I. for } \\
\text { OR }\end{array}$} & \multirow[t]{2}{*}{ p-value } \\
\hline \multicolumn{2}{|c|}{$\begin{array}{l}\text { Type of } \quad \text { profession } \\
\text { (Ref=community nurse) }\end{array}$} & & \multicolumn{2}{|l|}{$4.55-75.76$} & \\
\hline Nurse & 2.92 & 18.56 & $1.03-32.65$ & & $<0.001$ \\
\hline Midwife & 1.76 & 5.80 & $1.03-32.65$ & & 0.046 \\
\hline \multicolumn{2}{|c|}{ BMI (Ref= more than 30) } & & 0.854 & 0.23 & 2.26 \\
\hline $18.50-24.99$ & -0.33 & 0.72 & \multicolumn{2}{|l|}{$0.24-2.65$} & 0.574 \\
\hline $25.00-29.99$ & -0.22 & 0.80 & \multicolumn{2}{|l|}{$0.24-2.65$} & 0.711 \\
\hline \multicolumn{2}{|c|}{ Years of Experience $(\boldsymbol{R e f}=\mathbf{1 6}+)$} & & 0.188 & 0.04 & 41.27 \\
\hline $0-5$ & 0.30 & 1.35 & \multicolumn{2}{|l|}{$0.17-150.69$} & 0.865 \\
\hline $6-10$ & 1.63 & 5.12 & \multicolumn{2}{|l|}{$0.23-73.17$} & 0.344 \\
\hline $11-15$ & 1.40 & 4.07 & \multicolumn{2}{|l|}{$0.23-73.17$} & 0.341 \\
\hline \multicolumn{2}{|c|}{ Age $(\operatorname{Re} f=40+)$} & & 0.211 & 0.03 & 20.62 \\
\hline $20-30$ & -0.20 & 0.82 & \multicolumn{2}{|l|}{$0.02-6.10$} & 0.904 \\
\hline $31-40$ & -1.18 & 0.31 & & & 0.439 \\
\hline
\end{tabular}

Table 4 Participants' perceptions of job risk factors that may contribute to development of WMSDs (Greater than 7 on a scale of $0-10$ )

\begin{tabular}{|l|l|}
\hline Job risk factor & Percentage \\
\hline Performing the same task over and over & 35.6 \\
\hline Treating an excessive number of patients in one day & 30.7 \\
\hline Not enough rest breaks or pauses during the workday & 12.2 \\
\hline Working in awkward and cramped positions & 39.6 \\
\hline $\begin{array}{l}\text { Working in the same positions for long periods } \\
\text { (Standing, bend over, sitting, kneeling) }\end{array}$ & 35.8 \\
\hline Bending or twisting your back in an awkward way & 34.3 \\
\hline Working near or at your physical limits & 17.5 \\
\hline Reaching or working away from your body & 11.2 \\
\hline Continuing to work while injured or hurt & 6.0 \\
\hline Lifting or transferring dependent patients & 52.1 \\
\hline Working with confused or agitated patients & 5.7 \\
\hline $\begin{array}{l}\text { Carrying, lifting, or moving heavy materials or } \\
\text { equipment (e.g., continuous passive motion machines) }\end{array}$ & 13.4 \\
\hline Unanticipated sudden movement or fall by patient & 9.3 \\
\hline Assisting patients during gait activities & 7.5 \\
\hline $\begin{array}{l}\text { Work scheduling (Overtime, irregular shifts, } \\
\text { length of workday) }\end{array}$ & 6.0 \\
\hline Inadequate training on injury prevention & 46.5 \\
\hline
\end{tabular}

\section{Participants' perceptions of job risk factors}

The participants indicated that lifting or transferring of dependent patients, inadequate training on injury prevention and working in awkward or cramped positions as the most perceived job risk factors. Results are presented in Table 4.

\section{Coping strategies used by participants}

Getting help from colleagues in handling heavy patients, modifying patient's position/nurse's position and modifying nursing procedure were the most used coping strategy by the participants as shown in Table 5 .

Table 5 Participants' coping strategies for reducing WMSD

\begin{tabular}{|c|c|c|c|}
\hline \multicolumn{2}{|l|}{ Coping Strategy } & \multirow{2}{*}{$\begin{array}{l}\text { Number } \\
46\end{array}$} & \multirow{2}{*}{$\begin{array}{l}\text { Percent } \\
34.3 \%\end{array}$} \\
\hline $\begin{array}{l}\text { I get someone else to help me handle a } \\
\text { heavy patient }\end{array}$ & $\begin{array}{l}\text { Almost } \\
\text { Always }\end{array}$ & & \\
\hline & Sometimes & 73 & $54.5 \%$ \\
\hline & Never & 15 & $11.2 \%$ \\
\hline \multirow[t]{3}{*}{ I modify patient's position/ my position } & $\begin{array}{l}\text { Almost } \\
\text { Always }\end{array}$ & 44 & $32.8 \%$ \\
\hline & Sometimes & 81 & $60.4 \%$ \\
\hline & Never & 9 & $6.7 \%$ \\
\hline \multirow[t]{3}{*}{$\begin{array}{l}\text { I use a different part of my body in } \\
\text { administering my nursing procedure }\end{array}$} & $\begin{array}{l}\text { Almost } \\
\text { Always }\end{array}$ & 27 & $20.3 \%$ \\
\hline & Sometimes & 71 & $53.4 \%$ \\
\hline & Never & 35 & $26.3 \%$ \\
\hline \multirow[t]{3}{*}{$\begin{array}{l}\text { I warm up and stretch before perform- } \\
\text { ing my nursing duties }\end{array}$} & $\begin{array}{l}\text { Almost } \\
\text { Always }\end{array}$ & 6 & $4.5 \%$ \\
\hline & Sometimes & 46 & $34.3 \%$ \\
\hline & Never & 82 & $61.2 \%$ \\
\hline \multirow[t]{3}{*}{$\begin{array}{l}\text { I modify my nursing procedure in order } \\
\text { to avoid stressing an injury }\end{array}$} & $\begin{array}{l}\text { Almost } \\
\text { Always }\end{array}$ & 35 & $26.1 \%$ \\
\hline & Sometimes & 82 & $61.2 \%$ \\
\hline & Never & 17 & $12.7 \%$ \\
\hline \multirow[t]{3}{*}{$\begin{array}{l}\text { I pause regularly so I can stretch and } \\
\text { change posture }\end{array}$} & $\begin{array}{l}\text { Almost } \\
\text { Always }\end{array}$ & 20 & $14.9 \%$ \\
\hline & Sometimes & 76 & $56.7 \%$ \\
\hline & Never & 38 & $28.4 \%$ \\
\hline \multirow[t]{3}{*}{$\begin{array}{l}\text { I adjust plinth/bed height, so I can } \\
\text { stretch and change posture }\end{array}$} & $\begin{array}{l}\text { Almost } \\
\text { Always }\end{array}$ & 23 & $17.2 \%$ \\
\hline & Sometimes & 77 & $57.5 \%$ \\
\hline & Never & 34 & $25.4 \%$ \\
\hline \multirow[t]{3}{*}{$\begin{array}{l}\text { I select techniques/procedures that will } \\
\text { not aggravate or provoke my discomfort }\end{array}$} & $\begin{array}{l}\text { Almost } \\
\text { Always }\end{array}$ & 32 & $23.9 \%$ \\
\hline & Sometimes & 71 & $53.0 \%$ \\
\hline & Never & 31 & $23.1 \%$ \\
\hline \multirow[t]{3}{*}{$\begin{array}{l}\text { I stop a treatment if it causes or aggra- } \\
\text { vate my discomfort }\end{array}$} & $\begin{array}{l}\text { Almost } \\
\text { Always }\end{array}$ & 28 & $20.9 \%$ \\
\hline & Sometimes & 60 & $44.8 \%$ \\
\hline & Never & 46 & $34.3 \%$ \\
\hline
\end{tabular}

\section{DISCUSSION}

The aim of this study was to determine the prevalence of self-reported WMSDs, the possible risk factors and the coping strategies nurses and midwives used during their normal routine at work in a secondary healthcare facility in Ghana as a reference for further studies. 
In this present study, RGN reported 12-month prevalence of $79.0 \%$. The similarity in the prevalence of WMSDs among RGN clearly indicates that, globally, RGN experience high prevalence of WMSDs while discharging their duties. However, the slight disparity in the prevalence across countries could be ascribed to many factors. Such factors may include cultural difference in perception and reporting of pain, differences in organizational set up of work places, varying welfare and lopsided biotechnological advancements among the countries. Although there have been variations in the prevalence of WMSDs among RGN across boundaries, the prevalence has been generally high.

Previous studies showed 12-month prevalence of 78\% in south-west Nigeria ${ }^{7}, 81 \%$ in rural India, ${ }^{1}$ and $77.4 \%$ in China. A systemic review corroborated these findings with a mean prevalence of $71.9 \%{ }^{6}$

On the contrary there seems to be scarcity of data for WMSDs among midwives. A systemic review by Long et al. ${ }^{14}$ could only retrieve one publication concerning WMSDs among midwives out of the 29 publications included in the study. Two studies also examined the WMSDs among midwives extensively. A study by Rahimi et al., ${ }^{18}$ reported a higher 12- month prevalence of $67.6 \%$ among the midwives as compared to $53.8 \%$ prevalence in the current study. Ozgoli et al. ${ }^{19}$ reported a 12 - month prevalence of $36.3 \%$.

There has been consistency in literature about the most vulnerable body sites to WMSDs. Several studies across the globe, ${ }^{6,7,8,20}$ have indicated low back and neck as the two most susceptible body parts to WMSDs. This current study also found low back (72.0\%) and neck (37.0\%) to be the two most vulnerable body segments. It was not surprising though that this current study revealed highest prevalence $(72.0 \%)$ for low back. Low back pain (LBP) has been reported as the most common musculoskeletal disorder in adult accounting for a lifetime prevalence of $60-80 \%{ }^{21}$ In the nursing profession generally, a lifetime prevalence of LPB $35-80 \%$ has been documented and it was largely attributed to awkward working posture assumed during patient transfers, strenuous physical demands of the nursing profession, deconditioning status and obesity. 6.7 .

Out of the 93 participants who reported WMSDs within the last 12 months, $61.3 \%$ had resorted to selfmedication because of pain or discomfort. This finding was not unexpected as some authors ${ }^{23}$ have indicated self-management as common practice among the nurses presumably due to their healthcare knowledge. Aside from this, $24.7 \%$ of the participants had also consulted physiotherapist for professional advice and/or management. Although there are plethora of management strategies available to nurses and midwives for the preven- tion and treatment of WMSDs, some authors have suggested physiotherapy modalities such as therapeutic exercises to effectively negate the secondary effect of WMSDs.

A systemic review by Rodrigues et al. ${ }^{23}$ concluded that, strength exercises with intensity of $70-85 \%$ of repetitive maximum performed in the workplace, three times a week for 20 minutes can alleviate musculoskeletal pain. Ellapen and Narsigan, ${ }^{6}$ suggested that adherence to regular supervised exercise programs can militate against WMSDs and injuries among nurses. It thus implies that education on preventive measures and treatment options available for alleviating WMSDs could be employed to modify the rise in the prevalence among the nurses and midwives.

\section{Association between prevalence of WMSDs and so- cio-demographic characteristics}

The finding in this study showed a strong association between the prevalence of WMSDs and types of profession. RGN are about $19 \mathrm{x}(\rho<0.001, \mathrm{OR}=18.56$, $\mathrm{CI}=4.55,75.768)$ more likely to develop WMSDs than RCHN. Also, WMSDs is more likely to occur about 6 times among the RM than the RCHN. This finding could be tied to the background knowledge of the RCHN which tends to put them at advantaged position over RGN and RM for disease prevention, health promotion, community mobilization, health information and advocacy.

In addition, the job description of the RCHN involves less risk factors of WMSDs than RGN and RM, hence the lower point-prevalence recorded in our study. Musculoskeletal disorders are said to be common among health professionals who are in direct contact with patients. $^{7}$ Current literatures ${ }^{6,24}$ have established a link between WMSDs and healthcare professions that are involved in transferring of dependent patients, lifting of items and regular turning of patients which largely precludes RCHN.

In our study majority of the nurses (61.2\%) were either overweight or obese. Regression analysis reviewed that those with healthy body weight are less likely (OR 0.72 , CI $0.23,2.26$ ) to develop WMSDs than the obese participants. However, there was no significant correlation between the BMI and the risk of developing WMSDs. This finding differs from the finding by Choobineh et al. ${ }^{11}$ and Naidoo and Coopoo ${ }^{13}$ where obesity among nurses was found as a primary intrinsic predisposing factor of low back pain.

Our study revealed that nurses with more than 16 years of clinical practice, experience lower risk of WMSDs than those with lesser years of clinical practice. 
This could be ascribed to the fact that experienced nurses have increased level of knowledge about injury prevention, avoid harmful physical load, and have developed better coping strategies for musculoskeletal problems than the less experienced nurses. Additionally, nurses with more years of clinical practice may be involved more in administrative work than patient handling. This result corroborates the findings of Tinubu et $a .^{7}$

Considering the number of working hours per week and the risk of WMSDs, previous studies indicated that increase number of working hours increases the risk of WMSDs. However, there was no significant association between the 12-months prevalence and the number of working hours per week $\left(\mathrm{x}^{2}=0.895, \mathrm{P}\right.$-value 0.93$)$ in this present study. This could be due to the fact that, the current study is an institution- based and most of the participants have the same number of allocated working hours. The few ones who had less working hours were breastfeeding mothers and some senior staffs who are in supervisory role stay bit longer after work for administrative duties.

\section{Perceived Risk Factors}

From the present findings, lifting or transferring of dependent patients, inadequate training on injury prevention, working in awkward or cramped positions and working in the same positions for long periods were the most perceived job risk factors. This finding is similar to the previous studies. ${ }^{6,7,26}$ According to the theory of fear of avoidance, an individual tends to identify a harmful stimulus and tries to avoid it for further unpalatable experience. ${ }^{25}$ In like manner, nurses and midwives have identified some risk factors that cause them discomfort or pain in the discharge of their normal duties.

\section{Coping Strategies}

Health professionals adopt certain strategies to reduce the occurrence/re-occurrence of WMSDs. From this study, getting help from a colleague in handling a heavy patient, modifying patient's position/nurse's position and modifying nursing procedure were the most used coping strategies in reducing WMSDs. Similar findings on coping strategies have been previously reported. . $^{1,726}$ The strategies were adopted by the participants possibly because of their past experiences in single handling a heavy patient or their comfortability in modifying the caring procedure, either through their position or that of their /the patients.

\section{CONCLUSION}

The findings of this study establish a high prevalence of self- reported WMSDs mostly in the low back, neck and upper back among general nurses and midwives working at LEKMA hospital.
This study also establishes that the cadre of nursing is the only strong predictive factor of the incidence of WMSDs among the sampled health workers. It thus implies that in addition to self-adopted coping strategies to reduce the effect of WMSDs among the nurses, periodic education on body mechanics is imperative to alleviate the risk factors.

\section{ACKNOWLEDGEMENT}

We acknowledge the management of LEKMA hospital and all the participants of this study

\section{REFERENCES}

1. Anap DB, Iyer C, Rao K. Work related musculoskeletal disorders among hospital nurses in rural Maharashtra, India: a multi-centre survey. Int $J$ Res Med Sci 2013; 1:101-7.

2. Cheila ML, Maria RBB, Fabiana CTF, Fernanda LRR, Maria HPM, Maria LCCR. Work-related musculoskeletal disorders in nursing professionals: an integrative literature review. Acta Paul Enferm 2012. 25(3):477-82.

3. Murofuse NT, Marziale MH. Diseases of the osteomuscular system in nursing workers. Rev Latinoam Enferm 2005;13(3):364-73. Portuguese

4. Walsh IA, Corral S, Franco RN, Canetti EE, Alem ME, Coury HJ. Work ability of subjects with chronic musculoskeletal disorders. Rev Saúde Pública 2004;38(2):149-56. Portuguese

5. Tsekoura Maria, Koufogianni Andrianna, Billis Evdokia, Tsepis Elias. Work - Related Musculoskeletal Disorders Among Female and Male Nursing Personnel In Greece. WJRR 2017; 3(1);08-15

6. Ellapen TJ, Narsigan S. Work- Related Musculoskeletal Disorders among Nurses: systemic review. J Ergonomics 2014; S4:S4-003:1-6

7. Tinubu BMS, Mbada CE, Oyeyemi AL, Fabunmi AA. Work-Related Musculoskeletal Disorders among Nurses in Ibadan, South-west Nigeria: a cross-sectional survey. BMC Musculoskelet Disord 2010;11(12): 1-8.

8. Majumdar D, Pal MS, Majumdar D. Work-related Musculoskeletal Disorders in Indian Nurses: A Cross-sectional Study. J Nov Physiother 2014; 4(3):1-7

9. Punnett L, Wegman DH: Work-related musculoskeletal disorders: the epidemiologic evidence and the debate. Journal of Electromyography and Kinesiology 2014; 14:13-23.

10. Daraiseh Nm, Cronin SN, Davis LS, Shell RL,Karwowski W et al. Low back symptoms among hospital nurses, associations to individual factors and pain in multiple body regions. International Journal of Industrial Ergonomics 2010; 40(1): 19-24.

11. Choobineh A, Rajaeefard A, Neghab M (2010) Association between perceived demands and musculo- 
skeletal disorders among hospital nurses of Shiraz University of Medical Sciences: a questionnaire survey. Int J Occup Saf Ergon 12: 409-416.

12. Skotte J, Fallentin N. Low back injury risk during repositioning of patients in bed: the influence of handling technique, patient weight and disability. Ergonomics 2008; 51: 1042-1052.

13. Naidoo R, Coopoo Y. The health and fitness profiles of nurses in KwaZulu-Natal. Curationis 2007; 30: 66-73.

14. Long MH, Bogossian FE, Johnston V. The prevalence of Work-related Neck, Shoulder and Upper Back Musculoskeletal Disorders among Midwives, Nurses and Physician: A systemic review. Workplace Health and Safety 2013; 61(5): 223229

15. World Health Organization (2015), Identification and Control of Work-related Musculoskeletal Diseases, WHO 2015 p.174.

16. The Health Sector in Ghana (2015). Facts and Figures. Available:

https://www.ghanahealthservice.org/downloads/F IN-

AL\%20_23_06_2015\%20Facts\%20and\%20figur es.pdf

17. Lipscomb, J., Trinkoff, A., Brady, B., \& GeigerBrown, J. Health care system changes and reported musculoskeletal disorders among registered nurses. Am J Public Health 2004; 94:1431-5.

18. Rahimi Ms, Mojtaba E, Mahmood M, Moosazadeh M, Narges K, Mohamad Nl, Elham R. Musculoskeletal Disorders and its Relation with Job Stress in Midwives. IJOH 2017;9:38-45

19. Ozgoli G, Bathaei AAS, Mirmohamadali M, Alavi MM. Musculoskeletal Symptoms Assess- ment among Midwives, Hamedan. Iran Occupational Health J 2006; 3(1);37-42

20. Yan P, Li F, Zhang L, Yang Y, Huang A, Wang $\mathrm{Y}$ and Yao H. Prevalence of Work-related Musculoskeletal Disorders in the Nurses working in Hospitals of Xinjiang, Uygur Autonomous Region. Pain Research and Management 2017;1-7 https://doi.org/10.1155/2017/5757108

21. Waddell G, Burton AK: Occupational health guidelines for the management of low back pain at work. Occupational Medicine 2001,51:124135.

22. Ribeiro TM, Florentin S, Helena L. Work related Musculoskeletal Disorders in primary Health Care Nurses. Applied Nursing Research 2016;33(2017);72-77

23. Rodrigues EV, Gomes ARS, Tanhoffer AIP, Leite N. Effects of exercise on pain of musculoskeletal disorders: a systematic review. Acta Ortop Bras. [online]. 2014;22(6):334-8.

Available from URL: http://www.scielo.br/aob.

24. Mirmohammadi S, Yanzdani J, Etemadinejad S, Asgarinejad H. A cross-sectional study on workrelated musculoskeletal disorders and associated risk factors among hospital healthcares: procedia manufacturing 2015;3:4528-4534

Available: www.sciencedirect.com

25. Michaella B. Two - factor theory of learning: application to maladaptive behavior: Health Education, Contexts and Inspiration 2010;21:333338

26. Gopal K, Thomas M, Sreedharan J. Work-related Musculoskeletal Disorders in Hospital Nurses: Prevalence and Coping Strategies. GMJ,ASM 2012;1(1): 159- 